CDD: 658.406

\title{
FATORES FACILITADORES DA INTELIGÊNCIA ORGANIZACIONAL: O PAPEL DAS UNIDADES DE INFORMAÇÃO
}

\section{FACILITATIVE FACTORS TO ORGANIZATIONAL INTELLIGENCE: THE ROLE OF INFORMATION UNITS}

\author{
Delsi Fries Davok ${ }^{1}$ \\ Daiana Lindaura Conti ${ }^{2}$
}

\begin{abstract}
Resumo: Artigo de revisão que apresenta fatores facilitadores para o desenvolvimento da inteligência organizacional, enfocando o papel das unidades de informação nesse contexto. Define a temática a partir de pesquisa bibliográfica exploratória, compreendendo 15 artigos de periódicos nacionais das áreas de Biblioteconomia e Ciência da Informação. Realizou-se leitura analítica dos artigos e interpretação referencial dos dados relativos a categorias de análise estabelecidas, o que possibilitou a identificação de fatores facilitadores para o desenvolvimento da inteligência organizacional. Concluiuse que, dependendo do contexto, os principais fatores que facilitam o processo de consolidação de um sistema de inteligência organizacional são: cultura organizacional, redes sociais, gestão do conhecimento, gestão da informação, tecnologias da informação e comunicação, inovação tecnológica, estrutura organizacional, e prospecção e monitoramento da informação. Tendo em vista esses resultados, propõe-se a realização de novos estudos sobre o tema utilizando outras fontes de informação para que se aprofunde a temática.
\end{abstract}

Palavras-chave: Inteligência Organizacional - Fatores Facilitadores. Inteligência Competitiva. Unidades de Informação - Inteligência Organizacional.

Abstract: The present article is a review of the facilitative factors for the development of organizational intelligence, focusing on the role of the information units in this context. It defines the theme based on an exploratory bibliographical investigation, comprehending 15 articles from national journals in the Library Sciences and Information Sciences fields. An analytical reading of the articles was done, as well as a referential interpretation of the data relative to predetermined categories of analysis, which enabled the identification of facilitative factors to the development of organizational intelligence. It is concluded that, depending on the context, the main factors that facilitate the process of consolidation of an organizational intelligence system are: organizational culture, social networks, knowledge management, information management, information and communication technology, technological innovation, organizational structure, and prospection and information monitoring. Based on these results, we propose new studies on the subject making use of other information sources so as to further comprehend it.

Keywords: Organizational Intelligence - Facilitative Factors. Organizational Intelligence - Obstacles. Competitive Intelligence. Information Units - Organizational Intelligence.

\footnotetext{
${ }^{1}$ Doutora em Engenharia de Produção pela Universidade Federal de Santa Catarina. Professora do Departamento de Biblioteconomia e Gestão da Informação(DBI), e Coordenadora de Avaliação Institucional da Universidade do Estado de Santa Catarina. Brasil. E-mail: delsi@ davok.com.br ${ }^{2}$ Bacharel em Biblioteconomia - Gestão da Informação pela Universidade do Estado de Santa Catarina (UDESC). Bibliotecária da Escola Sarapiquá, Florianópolis, SC. E-mail: daiconti@ hotmail.com
} Enviado em: 17/09/2012 - Aceito em: 19/03/2013. 


\section{INTRODUÇÃO}

As mudanças proporcionadas por fatores como o desenvolvimento econômico, científico, tecnológico, dos meios de produção, da gestão empresarial, da difusão da mídia, provocaram a mudança da sociedade industrial para a sociedade do conhecimento, na qual a informação é o valor principal. Porém, não basta ter a informação, ela precisa ser disseminada e compartilhada para que se transforme em conhecimento e, por conseguinte, em inteligência organizacional e vantagem competitiva entre empresas e nações.

$\mathrm{Na}$ literatura, a inteligência organizacional, por vezes, é tratada como inteligência competitiva, por outras, os dois conceitos são diferenciados. No entanto, neste artigo adotou-se o pressuposto de que as duas temáticas não são excludentes, porém complementares, entendendo-se a inteligência competitiva como um processo para o desenvolvimento da inteligência organizacional.

Nessa linha, Rezende (2002, apud Rezende, 2003, p. 28) afirma que a inteligência organizacional é “[...] a somatória dos conceitos de inovação, criatividade, qualidade, produtividade, efetividade, perenidade, rentabilidade, modernidade, inteligência competitiva e gestão do conhecimento"; e a inteligência competitiva é, na concepção de Gomes e Braga (2001, p. 28), “[...] o resultado da análise de dados e informações coletados do ambiente competitivo da empresa que irão embasar a tomada de decisão, pois gera recomendações que consideram eventos futuros e não somente relatórios para justificar decisões passadas".

Assim, entendendo-se a inteligência competitiva como parte de um todo maior, que é a inteligência organizacional, neste artigo também se considerou seus fatores facilitadores.

Existem fatores que facilitam o desenvolvimento da inteligência organizacional e as organizações, para tal, precisam investir na capacitação das pessoas e estar preparadas para desafiar as exigências do mundo do trabalho e do sistema de mercado. É necessário também que os tomadores de decisão tenham acesso e utilizem informações confiáveis, oportunas e estratégicas para colocar a organização à frente da concorrência e criar diferencial competitivo. Logo, a informação é o ponto de partida para a organização desenvolver a inteligência organizacional e assim manter-se atuante no mercado. 


\section{INTELIGÊNCIA ORGANIZACIONAL}

Embora não se encontre na literatura um estudo mais profundo sobre a origem do tema, há registros do uso de técnicas de inteligência para a tomada de decisão ao longo da história, desde a antiguidade, por exércitos, governos e nos negócios. Juhari e Stephens (2006) apresentam um panorama de fatos históricos que revelam o uso da inteligência desde 1000 a.C., quando era usada no escambo e comércio de mercadorias e serviços e em guerras para conquista de territórios, até o Século XXI, quando o uso da inteligência é cada vez mais necessária para as organizações garantirem sua competitividade e sobrevivência, e estudos são desenvolvidos para melhorar métodos e ferramentas a fim de consolidar a disciplina.

A inteligência tem merecido maior atenção das organizações, aliada ao planejamento estratégico, desde a II Guerra Mundial, quando foi utilizada para a obtenção de informações sobre o inimigo. Nessa época foram, "[...] criados os primeiros setores de inteligência, geralmente ligados aos setores de espionagem" (CANTO, 2005, p. 12).

Atualmente, a inteligência organizacional diz respeito à:

[...] capacidade das organizações (entre elas as unidades de informação) de
monitorar informações ambientais para responder satisfatoriamente aos
desafios e oportunidades que se apresentam continuamente. Pode-se dizer
que a inteligência visa, principalmente, a imprimir um comportamento
adaptativo à organização, permitindo que estas mudem e adaptem os seus
objetivos, produtos e serviços, em resposta a novas demandas do mercado
e a mudanças no ambiente (TARAPANOFF; ARAÚJO JÚNIOR;
CORMIER, 2000, p. 91).

Moresi (2001, p. 119) afirma que a inteligência é “[...] a informação como oportunidade, ou seja, o conhecimento contextualmente relevante que permite atuar com vantagem no ambiente considerado". Ainda, segundo Moresi (2001, p. 120), para existir inteligência é preciso que aconteça "A transformação de conhecimento em inteligência [...] que é uma habilidade puramente humana, baseada em experiência e intuição, e vai muito além da capacidade de qualquer sistema especialista ou de inteligência artificial”.

A inteligência organizacional, para Albrecht (2004, p. 3) é “[...] a capacidade da empresa de mobilizar todo seu potencial intelectual disponível e concentrar tal capacidade na realização de sua missão". 
Para Pereira e Cianconi (2008, p. 85-86), inteligência organizacional é tornar a informação estratégica para apoiar a tomada de decisão. Assim, a inteligência organizacional

[...] pode ser entendida como um processo contínuo sistemático de coleta, tratamento e análise da informação sobre o ambiente externo, em que a informação com valor agregado é transformada em inteligência e disseminada aos usuários do Sistema em apoio a tomadas de decisão, objetivando alcançar vantagens competitivas.

Logo, sistemas de inteligência monitoram os ambientes interno e externo, para que esse panorama, que muda constantemente, não seja ameaça para o funcionamento da organização e a superação de suas dificuldades.

Desse modo, inteligência organizacional é cultura organizacional não resistente a mudanças. Organizações inteligentes utilizam estrategicamente a informação para o gerenciamento eficaz e eficiente do conhecimento organizacional e tomadas de decisão efetivas.

Na visão de Rezende (2003, p. 28), a inteligência organizacional contempla “[...] os conceitos de modelagem estratégica de negócios, de inovação, de competitividade, de inteligência competitiva e de gestão do conhecimento".

Assim sendo, neste estudo entende-se a inteligência organizacional como um sistema que envolve o monitoramento dos ambientes interno e externo das organizações, e a inteligência competitiva como um dos processos desse sistema.

A inteligência competitiva é foco de inúmeros estudos, gerando publicações de artigos de pesquisas e de relatos de práticas em organizações. Todavia, ainda não há consenso quanto a sua definição conceitual, pois se percebe que cada área define a inteligência competitiva conforme seu campo de atuação, o que vem causando confusões com outros conceitos, como inteligência organizacional e inteligência empresarial. Na concepção de Valentim et al (2003) a inteligência competitiva é um processo essencial para a organização planejar suas estratégias, ações táticas e operacionais, suprir suas necessidades de informação em diferentes níveis de complexidade, e para as pessoas desenvolverem suas atividades profissionais tendo em vista o mercado, a competitividade e a globalização. Nascimento (2006, p. 58) afirma que:

A essência da Inteligência Competitiva é o manuseio de informações de mercado, informações tecnológicas, informações sobre clientes e concorrentes, como também informações relativas a tendências externas, 
políticas e socioeconômicas, oriundas de comunicações verbais e escritas, como documentos oficias e pessoais, entrevistas, relatos de reunião, programas de rádio e $\mathrm{TV}$, internet, entre outros.

As organizações que se mantêm competitivas no mercado são aquelas que sabem gerenciar as informações para o processo decisório. Moreno (2007, p. 13) afirma que "A agilidade e confiabilidade das informações são fundamentais para o sucesso do processo de tomada de decisão". A tomada de decisão, no entendimento de Moresi (2001, p. 116), “[...] é muito mais do que o momento final da escolha e é um processo complexo de reflexão, investigação e análise”. Desse modo, “[...] o volume de informações e de dados colocados à disposição do decisor deve ser na medida certa” (MORESI, 2000, p. 18). Portanto, é necessário que “[...] as informações sejam, oportunas, relevantes, organizadas, disponibilizadas a fim de orientar os atores dos diferentes processos organizacionais na tomada de decisão" (MORENO, 2007, p.14).

Já a estratégia, segundo Moreno (2007, p. 14), “[...] começou a ser utilizada pelas empresas significando o modo como as organizações se comportam e tomam decisões frente às alterações do ambiente". A informação estratégica, por sua vez, é recurso essencial para as organizações se manterem competitivas no mercado, tendo “[...] como principal objetivo o uso de dados, informação e conhecimento para agregação de valor a produtos e/ou serviços, garantindo a sobrevivência da organização aos desafios atuais" (CALAZANS, 2006, p. 64).

A informação estratégica possibilita à organização se antecipar a seus concorrentes e permanecer no mercado. Segundo Borges (1995, p. 13), “[...] a competitividade de uma empresa é diretamente proporcional à sua capacidade de obter informação, processá-la e disponibilizá-la de forma rápida e segura”. Assim sendo, a informação adquire caráter estratégico de apoio à tomada de decisão nas organizações. Para tal, a cultura organizacional deve se adaptar às constantes mudanças que ocorrem no ambiente externo das organizações.

O termo cultura surgiu no campo da antropologia social com o desenvolvimento de pesquisas sobre os modos de vida das sociedades primitivas. Segundo Duarte et al, (2000, p. 4), “[...] o conceito de cultura surgiu para representar, no sentido amplo, as qualidades dos grupos humanos que são repassadas de geração a geração". 
O conceito de cultura aplicado às organizações, segundo Duarte et al (2000, p. 2) surgiu, “[...] como resposta aos problemas de desintegração social, enfatizando as idéias comuns, formas de pensar e agir, valores, padrões e maneiras de trabalhar do capital humano". De acordo com esses autores, a pessoa ou o grupo que forma a organização também forma a cultura organizacional que, por sua vez, “[...] é repassada, assimilada e modificada pelos seus sucessores, mas nunca extinta" (2000, p. 11).

Para Valentim et al (2005, p. 191-192), a cultura organizacional “[...] é uma construção subjetiva que interfere no pensar e agir coletivos. Tal cultura começa com a criação da organização e se perpetua com a inclusão de novos indivíduos".

A cultura organizacional desempenha papel essencial em processos de mudanças. Segundo Pereira et al (2004, p. 5),

[...] pode ser um impasse a ser vencido para quaisquer intenções de modificações organizacionais, podendo gerar um bloqueio ao desenvolvimento de novas iniciativas, mas também pode ser a mola mestra do impulso às revitalizações, tudo depende da maneira como a cultura foi formada.

Sendo assim, quando as organizações não alcançam o fim desejado, é momento de analisarem se a cultura organizacional não está interferindo no alcance de objetivos estratégicos. Davenport e Abrão (2003, p. 109), afirmam que as “[...] empresas raramente identificam em que o comportamento e a cultura devem mudar, para que suas iniciativas informacionais obtenham êxito". Logo, para garantir êxito às mudanças, necessárias devido ao cenário social e mercadológico, a cultura organizacional deve "[...] garantir o envolvimento e a colaboração das pessoas, promover o compartilhamento da informação e do conhecimento e promover a integração entre pessoas e subunidades organizacionais" (HENRIQUE; BARBOSA, 2005, p. 12).

A cultura organizacional deve ser não resistente às mudanças e favorável ao compartilhamento da informação e do conhecimento nas organizações. Valentim e Gelinski (2005, p. 48) afirmam que, além disso, também é necessário um ambiente físico favorável, considerando que "[...] organizações com muitas paredes/divisórias, mesas/armários etc., sem perceber bloqueiam a socialização do conhecimento".

Ademais, para que o conhecimento seja construído e posteriormente disseminado e compartilhado para a organização, Morin (apud VALENTIM; 
GELINSKI, 2005, p. 49) afirma que são necessárias “[...] atitudes voltadas a: 'aprender a aprender', 'aprender a pensar' e 'aprender a questionar"'. Sendo que “[...] a socialização do conhecimento pressupõe atitudes voltadas a: 'aprender a compartilhar', 'aprender a compreender' e 'aprender a diversidade intelectual'”. Logo, a disseminação e o compartilhamento do conhecimento organizacional e a disponibilização deste de forma facilitada aos colaboradores são influenciados pela cultura organizacional.

O conhecimento organizacional consolidado e sua gestão são aspectos fundamentais para o desenvolvimento da inteligência organizacional. Porém, não há consenso entre os pesquisadores de que seja possível fazer gestão de conhecimento (GC). Nessa linha, Terra (2005, p. 2) afirma que:

[...] o conhecimento em si não pode ser diretamente gerenciado. Para entender isto é importante lembrar que gerenciar conhecimento é bem diferente de gerenciar informação e dados. Conhecimento, de fato, só existe na cabeça das pessoas. Portanto é algo "invisível" e um pouco abstrato para a maior parte das pessoas que aprenderam a gerenciar "coisas".

Valentim e Gelinski (2005, p. 54), por sua vez, contra argumentam:

[...] se entendermos gestão do conhecimento como um conjunto de estratégias de ação que visam fomentar a criação, o compartilhamento/socialização e a retroalimentação do conhecimento humano, em um determinado espaço organizacional, sem dúvida nenhuma a gestão do conhecimento é possível.

Outros autores, como Gutiérrez (2006, p. 123), entendem que o conhecimento organizacional é "“...] aquele que se pode atribuir a uma organização, ou seja, o conhecimento próprio da organização. E [...] costuma estar representado materialmente em algum tipo de documento", como por exemplo, “[...] as bases de dados adquiridas por uma organização ou a propriedade intelectual e as patentes que esta desenvolve $[\ldots] ”$.

Embora haja opiniões divergentes quanto à gestão do conhecimento organizacional, há consenso quanto à sua importância para a sobrevivência da organização desde a década de 1950, quando pela primeira vez foi mencionado o conceito de trabalhador do conhecimento. Mas, somente no final da década de 80 
surgiram conceitos que ligavam a gestão do conhecimento às tecnologias da informação e comunicação (SANTOS; PAIM, 2000).

Para Terra $(2005$, p. 2), no que se refere ao conhecimento nas organizações, “[...] o que importa são as manifestações do conhecimento de cada indivíduo que, com suas ações e decisões, agregam valor aos processos de que participa". Sendo assim, a GC se ocupa "[...] dos processos gerenciais e infra-estrutura física e digital que facilitam, favorecem e estimulam os processos humanos de criação, compartilhamento e uso de conhecimentos individuais e coletivos".

Silva (2003, p. 117) considera que a GC nas organizações é algo essencial, pois:

\begin{abstract}
Ela vem da necessidade de que a organização saiba sobre os seus "saberes", conhecimentos tácitos, de forma registrada, o que implica captação do conhecimento tácito individual dos seus colaboradores. Essa captação, o armazenamento ou registro organizado em máquina, que torna o conhecimento acessível, informação novamente, é o que se entende, aqui, por gestão do conhecimento.
\end{abstract}

Segundo Duarte (2003, p. 283), a GC “[...] consiste na integração de processos simultâneos desde a criação ao uso pleno do conhecimento viabilizado pela cultura de aprendizado e de compartilhamento, no ambiente das organizações”. Para Cândido e Araújo (2003, p. 39), a GC é “[...] um conjunto de técnicas e ferramentas que permitem identificar, analisar e administrar, de forma estratégica e sistêmica, o ativo intelectual da empresa e seus processos associados". A GC também pode ser entendida como “[...] a gestão dos ativos intangíveis baseada, sobretudo, na competência dos colaboradores de uma determinada organização" (ROSSETI; MORALES, 2007, p. 127).

Na visão de Tarapanoff (2004, p. 22-23), a GC

[...] é um processo sistemático, articulado e intencional, apoiado na identificação, geração, compartilhamento e aplicação do conhecimento organizacional, com o objetivo de maximizar a eficiência e o retorno sobre os ativos de conhecimento da organização [...] não é uma atividade independente, ele está intrinsecamente ligado ao processo de gestão da informação e ao preparo (trabalho e análise) da informação em apoio à tomada de decisão, ambos alimentam o ciclo da inteligência e produzem a inteligência. 
Na opinião de Pereira (2005), a gestão do conhecimento nas organizações pode se dar por meio de: captação, armazenagem, recuperação e distribuição de ativos tangíveis de conhecimento, como patentes e direitos autorais; coleta, organização e disseminação de conhecimentos intangíveis, como know-how e especialização profissional, experiência individual, soluções criativas; e criação de um ambiente de aprendizado interativo para as pessoas transferirem o conhecimento, internalizá-lo e aplicá-lo na criação de novos conhecimentos.

Essas ações são atividades inerentes às unidades de informação, que, portanto, são instituições auxiliares à eficácia da GC por cuidarem de acesso, compartilhamento, socialização e transferência de informações e conhecimento para organizações de todos os tipos desenvolverem seus sistemas de inteligência organizacional.

É essencial para as organizações que as informações sejam gerenciadas de forma eficaz e eficiente, a fim de transformá-las em conhecimento organizacional e, consequentemente, sistematizar a inteligência organizacional. Nesse sentido, as unidades de informação são ambientes organizacionais onde pode ser sistematizada, gerida e desenvolvida a inteligência organizacional, entendendo que

[...] a postura competitiva associa-se à pró-atividade no atendimento às demandas dos usuários, ou seja, está intimamente relacionada à melhor oferta de produtos e serviços, à antecipação às novas tendências em relação a novas estruturas, à facilidade de acesso à informação, à formação, à agregação de valor e qualidade a esses produtos, bem como à sua personalização (customização), função de redes e de posicionamento no mercado de acordo com as demandas específicas (TARAPANOFF; ARAÚJO JÚNIOR; CORMIER, 2000, p. 94).

A competitividade e a dinâmica do mundo do trabalho exigem que o bibliotecário se qualifique constantemente, tenha diferencial perante outros profissionais da informação, saiba lidar com as tecnologias de informação e comunicação, e esteja apto para atuar em outras áreas, além das tradicionais da biblioteconomia, como tratamento temático, representação descritiva e indexação da informação. Em relação a isso, Canto (2005, p. 7) afirma que “A exigência agora é por profissionais que consigam aliar competências técnicas com habilidades pessoais, capacidade de trabalhar e se relacionar em equipe e que se mantenham em constante atualização”. 
Tendo em vista esse panorama, o bibliotecário precisaria “[...] redefinir o seu perfil profissional e ampliar seus conhecimentos e competências, readequando as suas antigas técnicas a esse novo cenário tecnológico e principalmente adotando uma nova postura de trabalho frente às exigências requeridas pelo mercado atual" (CANTO, 2005, p. 8).

O bibliotecário, tendo em vista os atuais currículos dos cursos de graduação, pode ser gestor da informação e mediador no desenvolvimento da inteligência organizacional. Dessa forma, em relação à utilização da informação como um recurso estratégico e de valor agregado,

As atividades do bibliotecário podem incluir: treinamento, trabalho especializado e atendimento a consultas dos usuários sobre seleção de fontes de informação; desenvolvimento de estratégias de pesquisa/busca; avaliação da informação (TARAPANOFF; ARAÚJO JÚNIOR; CORMIER, 2000, p. 93)

Além disso, nesse contexto, o gestor da informação também

[...] pode participar do planejamento e das atividades decisórias da organização, onde exerce o processamento, reunião e coleta de informações ambientais pertinentes à organização (vigilância informacional), procurando desenvolver um entendimento íntimo de como a informação é usada. Deve buscar entender qual o impacto da informação adquirida no desenvolvimento do indivíduo e da organização, além de procurar saber como os conhecimentos de cada um podem beneficiar a todos e a organização (CHOO, 1998, p.215; Quinn; Anderson \& Filkenstein, 1996 apud TARAPANOFF; ARAÚJO JÚNIOR; CORMIER, 2000, p. 93).

O campo para atuação do bibliotecário é cada vez mais vasto, havendo grandes possibilidades de atuação, mas, são necessárias mudanças no perfil profissional, que deve agregar novas competências e habilidades para que possa dar conta das demandas de seu mundo de trabalho. Assim sendo, Oliveira e Lacerda (2007) apresentam habilidades e competências que podem ser desenvolvidas por profissionais de inteligência competitiva no ciclo da IC. O bibliotecário, desenvolvendo as habilidades e competências necessárias também pode atuar com o desenvolvimento da inteligência organizacional e com a inteligência competitiva, pois, segundo os autores (2007, p. 47),

[...] o aumento da concorrência, proporcionado pelo processo da globalização, pelos avanços tecnológicos e pela onda de fusões e aquisições que assolaram o mundo nas últimas décadas, tem gerado a necessidade de as organizações manterem as melhores práticas de IC e criado um cenário propício para debater as habilidades e competências desejadas aos profissionais de IC nesse início de milênio. 
Amaral, Garcia e Alliprandini (2008, p. 6) apresentam como competências para as equipes de inteligência competitiva: “[...] relacionamento interpessoal; capacidade analítica; coleta de informações, comunicação; trabalho em equipe; e organizar e gerenciar processos".

Portanto, as mudanças da sociedade industrial para a sociedade do conhecimento impactaram no papel do bibliotecário, tanto em sua relação com o cliente da informação como no posicionamento das unidades de informação nas organizações. Hoje o bibliotecário precisa ter, além das competências tradicionais de organização e recuperação da informação, competências para tornar a informação acessível, apoiar e gerir redes e sistemas de informação, administrar e disseminar informações estratégicas, exatas e oportunas. Ou seja, as unidades de informação devem atender às necessidades de informação das suas organizações mantenedoras, agregando valor a seus serviços e produtos e o bibliotecário precisa de competências específicas para atuar no desenvolvimento da inteligência organizacional e inteligência competitiva.

Dado o exposto, é possível inferir que as habilidades e competências do profissional de IC também são necessárias ao bibliotecário, assim sendo, a presença do bibliotecário pode ser fator facilitador para a efetiva implantação do sistema de inteligência organizacional.

\section{FATORES FACILITADORES DA INTELIGÊNCIA ORGANIZACIONAL}

Para levantar os fatores facilitadores do desenvolvimento da inteligência organizacional foi realizada uma pesquisa bibliográfica, exploratória, de abordagem qualitativa. $\mathrm{O}$ universo da pesquisa foi delimitado a cinco periódicos nacionais das áreas da Ciência da Informação e da Biblioteconomia, abrangendo o período 20002009, com Qualis CAPES: Ciência da Informação; DataGramaZero - Revista de Ciência da Informação; Encontros Bibli: Revista Eletrônica de Biblioteconomia e Ciência da Informação; Informação \& Sociedade: Estudos; Perspectivas em Ciência da Informação; e Transinformação.

Desse universo foram selecionados 15 artigos que tratam do tema, a partir de termos de busca localizados no título, nas palavras-chave ou no resumo, como: inteligência organizacional, conhecimento organizacional, informação organizacional, 
informação estratégica, comunicação da informação, cultura organizacional, clima organizacional, compartilhamento da informação e disseminação da informação. Esses termos foram definidos no decorrer da revisão da literatura, na medida em que se percebeu a associação deles com a inteligência organizacional.

Utilizou-se a técnica de análise de conteúdo (BARDIN, 1977) para a análise e interpretação dos dados, seguindo três etapas: leitura técnica do universo de artigos para seleção daqueles que formariam o corpus de texto; leitura analítica do corpus de texto para identificar e descrever as categorias de análise; e, análise e interpretação referencial do corpus de texto, cujo exercício possibilitou a explicação dos principais fatores que facilitam o processo de consolidação de um sistema de inteligência organizacional: cultura organizacional, redes sociais, gestão do conhecimento, gestão da informação, tecnologias de informação e comunicação, inovações tecnológicas, estrutura organizacional; e prospecção e monitoramento da informação.

A cultura organizacional - que propicia o acesso, a disseminação e o compartilhamento das informações e dos conhecimentos na organização - é fator indispensável para o êxito de um sistema de inteligência organizacional.

Valentim e Woida (2004, p. 1) abordam a cultura organizacional no processo de inteligência competitiva (IC). Nessa linha, afirmam que a IC é "[...] algo que pode ser construído visando alianças estratégicas, entre as pessoas e a organização. A cultura organizacional é fundamental para que a IC possa ser de fato uma realidade". As autoras afirmam também que a cultura organizacional "[...] possibilita uma dinâmica positiva à consolidação da ética convencionada pela organização, estabelecendo princípios, valores e crenças essenciais para a inteligência competitiva" (2004, p. 1). Sendo assim, é necessário que essa cultura possibilite mudanças comportamentais nos colaboradores quanto à troca de informações e conhecimentos, que são necessários para o desenvolvimento eficaz da inteligência competitiva que, como definido anteriormente, é considerada um dos processos do sistema inteligência organizacional.

Segundo Valentim et al (2005, p. 192),

A cultura organizacional voltada ao processo de IC é um processo de construção da realidade coletiva, conduzido por um líder, o qual define tanto os melhores elementos e processos culturais, como os comportamentos inerentes ao clima organizacional, visando motivar os indivíduos por meio de relações de compartilhamento de informações, conhecimento, experiência e condutas, a fim de atingir o objetivo 
organizacional.

Nesse sentido, a cultura organizacional também é elemento importante para que as organizações se mantenham competitivas, pois, por meio dela, o ambiente externo percebe o modo de atuação da organização no mercado. Além disso, a cultura transmite como a organização é e que tipo de atividades realiza tendo em vista a sua missão.

Todavia, a cultura organizacional também pode se tornar um fator causador de dificuldades para o desenvolvimento da inteligência organizacional, porque muitas pessoas acreditam que "[...] compartilhar dados, informação e conhecimento, significa perder o poder frente às outras pessoas da organização, uma vez que não será o único a pensar sobre aquela possibilidade ou cenário" (VALENTIM; WOIDA, 2004, p. 6).

Acerca disso, Valentim e Woida (2004) enfatizam que é difícil implementar um sistema de IC quando não há cultura organizacional propícia para a construção, socialização e compartilhamento de dados, informação e conhecimento. Assim, as organizações que possuem cultura não proativa e resistente a mudanças, não configuram um cenário adequado para o desenvolvimento da inteligência organizacional.

As redes sociais são instrumento estratégico para o desenvolvimento dos processos da inteligência competitiva, bem como importantes ferramentas de disseminação e rápido acesso à informação. Segundo Alcará et al. (2006, p. 144), são

[...] representadas por atores (nós da rede) que mantêm ligações entre si devido a um propósito específico, que as movimenta e as potencializa. As relações desenvolvidas nas redes sociais possibilitam o alcance de propósitos comuns e, quando empregadas estrategicamente, podem se tornar uma ferramenta para a competitividade organizacional.

Ademais " [...] a identificação das posições e das ligações dos atores na rede consolidam a visão e a função dos atores importantes para o processo de inteligência competitiva" (ALCARÁ et al, 2006, p. 151).

Assim, as redes sociais servem de apoio para a IC, pois “[...] podem se constituir estratégias para a viabilização do processo de inteligência competitiva por meio do fortalecimento da cultura informacional e pela abertura de novos espaços para o compartilhamento da informação e do conhecimento" (ALCARÁ et al, 2006, p. 148). 
O mapeamento das redes sociais contribui com a IC, visto que:

[...] revela as relações entre as pessoas da organização, identificando as que estão à margem da rede, podemos apontar a análise de redes sociais como uma das estratégias que contribuem para a consolidação de uma cultura organizacional voltada para o compartilhamento, além de estimular a interatividade entre as pessoas e intensificar a confiança mútua no ambiente organizacional. É importante salientar que esses são fatores fundamentais para o bom êxito do processo de inteligência competitiva (ALCARÁ et al., 2006, p. 152).

Portanto, o uso de redes sociais possibilita que os colaboradores da organização interajam e mantenham uma cultura organizacional de compartilhamento da informação e do conhecimento, contribuindo para a eficácia da inteligência organizacional.

A gestão do conhecimento (GC), segundo Valentim et al (2003, p. 11), é base para o processo de inteligência competitiva, porque quando as organizações pautam suas ações

“[...] na sistematização e na socialização do conhecimento de seus indivíduos para a formação do conhecimento organizacional baseado na coletividade, $[\ldots]$ obtêm uma maior vantagem frente à concorrência $\mathrm{e}$ potencializam a exploração de novas idéias para fomentar a inovação".

Valentin et al. (2003, p.12) também considera que a gestão do conhecimento:

[...] atua essencialmente nos fluxos informais de informação e no conhecimento tácito, resgatando informações internas fragmentadas e transformando-as em representações estruturadas e significativas (conhecimento explícito) capazes de auxiliar o processo de inteligência competitiva, [e consequentemente o sistema de inteligência organizacional], assim como corrigir ações em situações críticas, identificar oportunidades e gerar atividades antecipativas frente à concorrência.

Na concepção de Silva, Espínola e Vilar (2006, p. 99), “A GC depende de uma ação sistemática interna e externa à empresa voltada à captação, análise, tratamento e distribuição da informação. Essa ação é denominada Inteligência Competitiva”.

Valentim e Gelinski (2005 p. 43) afirmam que

No processo de inteligência competitiva, a gestão do conhecimento é responsável pelo gerenciamento do conhecimento produzido na organização. Atua junto aos fluxos informais, e tem como foco o capital intelectual ou capital humano da organização.

Sendo assim, a gestão do conhecimento é fator facilitador para o desenvolvimento da inteligência organizacional, com vistas à utilização da informação de forma estratégica na tomada de decisão para garantir competitividade. 
A gestão da informação objetiva a identificação e potencialização dos recursos de informação da organização, bem como a sua capacidade de informação, de ensinar a aprender e se adaptar às mudanças ambientais. Logo, a gestão da informação é suporte para o crescimento e desenvolvimento de organizações inteligentes, abertas a mudanças e à inovação (TARAPANOFF, 2001).

O atual contexto competitivo exige informações confiáveis e pertinentes para o planejamento organizacional. As informações são, portanto, insumo para o desenvolvimento dos planos estratégicos, táticos e operacionais das organizações. Ademais, para que a organização garanta seu desempenho, ela “[...] necessita de informações úteis, consistentes, confiáveis e acessíveis, uma vez que todas as funções corporativas estão, ou deveriam estar, direta ou indiretamente, ligadas à missão e aos objetivos" (VALENTIM et al, 2005, p. 256).

Moraes e Escrivão Filho (2006, p. 124) afirmam que

“[...] realizar a gestão da informação, passou a ser considerada uma atividade essencial à sobrevivência das empresas, à medida que estas perceberam sua grande importância como um recurso estratégico na organização".

Para Valentim et al (2008) a gestão da informação inicia-se com a identificação das necessidades de informação das pessoas e o mapeamento dos fluxos formais de informação, isto é, do conhecimento explícito, nos diferentes setores da organização. Posteriormente, procede-se a coleta, filtragem, análise, organização, armazenagem e disseminação da informação, com o objetivo de subsidiar as atividades cotidianas e os processos decisórios das organizações.

Para Tarapanoff (2004, p. 20), a GI é realizada da seguinte forma:

O ciclo da gestão da informação é iniciado quando se detecta uma necessidade informacional, um problema a ser resolvido, uma área ou assunto a ser analisado. É um processo que se inicia com a busca da solução do problema, da necessidade de obter informações sobre algo, e passa pela identificação de quem gera o tipo de informação necessária, as fontes e o acesso a informação, sua aquisição, registro, representação e recuperação, análise e disseminação da informação que quando usada aumenta o conhecimento individual e coletivo [...].

Segundo Valentim e Gelinski (2005), os fluxos de informação formais e informais fornecem informações para a IC de forma a dar segurança aos processos decisórios e melhorar os processos corporativos. Dessa forma, a IC e a inteligência organizacional se sustentam na gestão da informação e do conhecimento. 
A prática da gestão da informação, para facilitar a disponibilização, o acesso e o compartilhamento das informações, requer o apoio das tecnologias da informação.

As Tecnologias de Informação e Comunicação (TICs) são importantes instrumentos para as organizações, independente da área e do ramo de atividades. Segundo Rosseti e Morales (2007, p. 124), a tecnologia de informação e comunicação é

[...] utilizada por indivíduos e organizações, para acompanhar a velocidade com que as transformações vêm ocorrendo no mundo; para aumentar a produção, melhorar a qualidade dos produtos; como suporte à análise de mercados; para tornar ágil e eficaz a interação com mercados, com clientes e até com competidores.

Além disso, segundo os autores, a tecnologia oferece ferramentas de comunicação e gestão imprescindíveis para a operação e competividade da empresa no mercado e que viabilizam acesso aos principais insumos de agregação de valor a produtos, processos e serviços, isto é, a informação e o conhecimento.

Segundo Alcará et al (2006, p. 149), “O uso de tecnologias de informação também é extremamente útil para apoiar o processo de inteligência competitiva, possibilitando maior agilidade e segurança". Gomes e Braga (2001) são mais incisivos ao afirmarem que as tecnologias de informação apoiam todas as etapas do sistema de inteligência competitiva, sendo necessárias desde a identificação das necessidades de informação até o apoio ao planejamento estratégico. Entremeio são necessárias para a organização dos fluxos de informação, para identificação de oportunidades e ameaças, avaliar e monitorar concorrentes e tendências políticas e sociais que possam influir nos processos e no sucesso organizacional.

As TICs, segundo Valentim et al (2003, p. 23), “[...] em diferentes fases [...] respondem pela eficiência e eficácia do sistema" de inteligência competitiva. Logo, as TICs são ferramentas facilitadoras para o desenvolvimento da inteligência organizacional.

No entanto, as TICs, por si só, não são suficientes para alavancar a inteligência organizacional, sendo necessário, para tal, também o contato pessoal para se ter acesso à determinadas fontes de dados, informações e conhecimento. As tecnologias de informação e comunicação podem também ser fatores dificultadores, em especial quando o elemento humano não está preparado para usá-las adequadamente. Segundo 
Alcará et al (2006, p. 149), “Em algumas oportunidades tão importantes e ao mesmo tempo inacessíveis são necessárias verdadeiras empreitadas para o acesso a elas", especialmente quando faltam habilidades e competências aos gestores da informação para prover o acesso ao grande volume de informações disponíveis atualmente.

No atual contexto corporativo as organizações são pressionadas a buscar continuamente novos modelos organizacionais e de gestão, conhecimentos e inovações tecnológicas para garantir competitividade. Como afirma Valentim et al (2003, p. 14)

"A inovação tecnológica que utiliza a informação e o conhecimento para a produção e inserção no mercado de novos bens e serviços, é atualmente alavanca para o desenvolvimento, conseqüentemente referencial para a competitividade empresarial".

Acrescenta-se que,

A inteligência competitiva e a inovação tecnológica estão ligadas também por fatores imanentes que estão subjacentes aos dois processos, que são a informação e o conhecimento resultantes de ambos. A informação e o conhecimento procedente de um dos processos podem servir de base para o outro (VALENTIM et al, 2003, p. 16).

Portanto, para desenvolver inteligência, é imprescindível que as organizações acompanhem as inovações tecnológicas, atentem para uma eficaz e eficiente gestão da informação e do conhecimento, tenham estrutura organizacional e as atividades dos colaboradores bem definidas.

Por sua vez, estrutura organizacional adequada é fator determinante para a implantação de um sistema de inteligência organizacional. Para tal, é importante "[...] a organização definir em seu organograma uma unidade de trabalho especificamente voltada a desenvolver ações e atividades à gestão da informação, gestão do conhecimento ou inteligência competitiva na organização" (VALENTIM, 2002, p. 4).

Portanto, uma organização que não tem estrutura para o gerenciamento de seus fluxos de informação, formais e informais, possivelmente encontrará dificuldades no desenvolvimento da IC, GI e GC. Esses três processos são complementares e o desenvolvimento da inteligência organizacional requer que estejam em sintonia. Nesse sentido, a estrutura organizacional que não estiver preparada para o desenvolvimento desses processos, pode ser fator dificultador da inteligência organizacional. 
A Prospecção e o monitoramento da informação são fatores preponderantes para o bom funcionamento de um sistema de inteligência organizacional. Nesse sentido, Valentim et al (2003, p. 30) argumentam que

\begin{abstract}
Através da prospecção informacional é possível estabelecer um mapa inicial de fontes de dados, informação e conhecimento essenciais ao negócio da organização. O mapeamento de dados, informação e conhecimento, alimenta os diferentes sistemas de I.C. existentes na organização, estabelecendo uma dinâmica na entrada dos dados, informação e conhecimento.
\end{abstract}

Quando a prospecção e o monitoramento da informação são feitos de forma adequada,

[...] imediatamente percebe-se o resultado na eficiência do sistema de I.C., pois proporciona a entrada de dados, informação e conhecimento relevante ao negócio. A filtragem bem feita, também contribui para a eficácia dos resultados das pesquisas realizadas nos sistemas (VALENTIM; MOLINA, 2004, p. 59).

A prospecção e o monitoramento da informação tratam da contínua e proativa identificação, recuperação e disseminação de dados, informações e conhecimentos necessários para a organização gerir o seu negócio, e são atividades essenciais para o desenvolvimento de um sistema de inteligência organizacional.

\title{
CONSIDERAÇÕES FINAIS
}

A pesquisa revelou que os aspectos que mais influenciam no desenvolvimento da inteligência organizacional são: cultura organizacional, redes sociais, gestão do conhecimento, gestão da informação, tecnologias de informação e comunicação, inovações tecnológicas, estrutura organizacional; e prospecção e monitoramento da informação. O corpus de texto analisado apresenta de forma explícita ou implícita essas variáveis, que, dependendo do contexto, e das habilidades e competências do elemento humano envolvido, podem tornar-se fatores facilitadores ou dificultadores no desenvolvimento da inteligência organizacional.

O profissional envolvido com sistemas de inteligência organizacional é o profissional de inteligência competitiva (IC), todavia, o bibliotecário também precisa das competências e habilidades necessárias para trabalhar com a inteligência organizacional, uma vez que lida com o objeto informação. Assim sendo, o bibliotecário também é fator facilitador para o desenvolvimento da inteligência 
organizacional em unidades de informações e em outros tipos de organização, sendo sua participação importante para o efetivo desenvolvimento e implantação do sistema.

A temática inteligência organizacional e seus processos, como a inteligência competitiva, são pouco evidenciados nos periódicos analisados. Mas, apesar das limitações, os objetivos traçados foram atingidos. Recomenda-se, no entanto, ampliar o escopo da pesquisa, utilizando outras fontes de informação, como anais de congressos e eventos da área, bem como fontes de outras áreas, a fim de colher subsídios conceituais para o desenvolvimento de sistemas de inteligência organizacional em unidades de informação, visto que estas também são organizações que lidam com informações estratégicas, embora não tenham fins lucrativos. 


\section{REFERÊNCIAS}

ALBRECHT, Karl. Um modelo de inteligência organizacional. HSM Management, Barueri, n. 44, p. 1-5, mai./jun. 2004. Disponível em:

<http://br.hsmglobal.com/adjuntos/14/documentos/000/061/0000061256.pdf > Acesso em: 23 abr. 2009.

ALCARÁ, Adriana Rosecler et al. As redes sociais como instrumento estratégico para a inteligência competitiva. Transinformação, Campinas, v. 18, n. 2, p. 143-153, maio/ago. 2006. Disponível em: <http://revista.ibict.br/pbcib/index.php/pbcib/article/view/549>. Acesso em: 22 maio. 2009.

AMARAL, Roniberto Morato do; GARCIA, Leonardo Guimarães; ALLIPRANDINI, Dário Henrique. Mapeamento e gestão de competências em inteligência competitiva.

DataGramaZero : Revista de Ciência da Informação, Rio de Janeiro, v. 9, n. 6, dez. 2008. Disponível em: <http://www.datagramazero.org.br/dez08/Art_05.htm>. Acesso em: 15 mar. 2009.

BARDIN, Laurence. Análise de conteúdo. Lisboa: Edições 70, 1977.

BORGES, Mônica Erichsen Nassif. A informação como recurso gerencial das organizações na sociedade do conhecimento. Ciência da Informação, Brasília, v. 24, n. 2, 1995.

Disponível em: <http://revista.ibict.br/index.php/ciinf/article/viewPDFInterstitial/551/500>. Acesso em: 18 mar. 2009.

CALAZANS, Angélica Toffano Seidel. Conceitos e uso da informação organizacional e informação estratégica. Transinformação, Campinas, v. 18, n. 1, p. 63-70, jan./abr. 2006. Disponível em: <http://revistas.puccampinas.edu.br/transinfo/viewarticle.php?id=147>. Acesso em: 15 fev. 2009.

CÂNDIDO, Gesinaldo Ataíde; ARAÚJO, Nadja Macêdo. As tecnologias de informação como instrumento de viabilização da gestão do conhecimento através da montagem de mapas cognitivos. Ciência da Informação, Brasília, v. 32, n. 3, p. 38-45, set./dez. 2003. Disponível em: 〈http://www.scielo.br/pdf/ci/v32n3/19022.pdf〉. Acesso em: 5 ago. 2009.

CANTO, Fábio Lorensi do. Atuação do profissional bibliotecário em sistemas de inteligência competitiva. Florianópolis: 2005.60 p. Trabalho de Conclusão de Curso (Bacharel em Biblioteconomia) - Universidade do Estado de Santa Catarina (UDESC), Florianópolis, 2005. Disponível em: <http://www.pergamum.udesc.br/dadosbu/000000/000000000000/0000009C.pdf>. Acesso em: 21 mar. 2009.

DAVENPORT, Thomas H; ABRÃO, Bernadette Siqueira. Ecologia da informação: por que só a tecnologia não basta para o sucesso na era da informação. 6. ed. São Paulo: Futura, 2003. $316 \mathrm{p}$.

DUARTE, Emeide Nóbrega. Análise da produção científica em gestão do conhecimento: estratégias metodológicas e estratégias organizacionais. 2003. 300 p. Tese (Doutorado em Administração) - Universidade Federal da Paraíba. Disponível em: <http://201.2.114.147/bds/BDS.nsf/E76953411BD477C403256F900049115B/\$File/NT000A 345E.pdf>. Acesso em: 11 out. 2009.

DUARTE, Emeide Nóbrega et al. A cultura organizacional influenciando o comportamento do capital humano da biblioteca universitária. Informação \& Sociedade: Estudos, João Pessoa, v. 10, n. 2, p. 1-12, 2000. Disponível em: 
<http://www.ies.ufpb.br/ojs2/index.php/ies/article/view/333/255\%3E>. Acesso em: 13 mai. 2009.

GOMES, Elisabeth; BRAGA, Fabiane. Inteligência competitiva: como transformar informação em um negócio lucrativo. Rio de Janeiro: Campus, 2001, 120 p.

GUTIÉRREZ, Mario Pérez-Montoro. O conhecimento e sua gestão em organizações In: TARAPANOFF, Kira (Org). Inteligência, informação e conhecimento. Brasília: IBICT, UNESCO, 2006. p. 117-138.

HENRIQUE, Luiz Cláudio Junqueira; BARBOSA, Ricardo Rodrigues. Gestão da informação e do conhecimento organizacionais: em busca de uma heurística adaptada à cultura brasileira. Perspectivas em Ciência da Informação, Belo Horizonte, v. 10, n. 1, p. 4-17, jan./jun. 2005. Disponível em: <http://www.eci.ufmg.br/pcionline/index.php/pci/article/view/30/102>. Acesso em: 18 ago. 2009.

JUHARI, Ariff S.; STEPHENS, Derek. Tracing the origins of competitive intelligence throughout history. Journal of Competitive Intelligence and Management, v. 3, n. 4, p. 6182, 2006. Disponível em: 〈http://www.scip.org/files/JCIM/3.4.juhari.pdf〉. Acesso em: 07 mar. 2013.

MORAES, Giseli Diniz de Almeida; ESCRIVÃO FILHO, Edmundo. A gestão da informação diante das especificidades das pequenas empresas. Ciência da Informação, Brasília, v. 35, n. 3, p. 124-132, set./dez. 2006. Disponível em:

<http://revista.ibict.br/index.php/ciinf/article/viewArticle/779>. Acesso em: 31 ago. 2009.

MORENO, Nádina Aparecida. A informação arquivística e o processo de tomada de decisão. Informação \& Sociedade: Estudos, João Pessoa, v. 17, n. 1, p. 9-19 jan./abr. 2007.

Disponível em: <http://www.ies.ufpb.br/ojs2/index.php/ies/article/view/483/1461>. Acesso em: 22 mar. 2009.

MORESI, Eduardo Amadeu Dutra. Delineando o valor do sistema de informação de uma organização. Ciência da Informação, Brasília, v. 29, n. 1, p. 14-24, jan./abr. 2000.

Disponível em: <http://revista.ibict.br/ciinf/index.php/ciinf/article/view/246/214>. Acesso em: 18 mar. 2009.

MORESI, Eduardo Amadeu Dutra. Gestão da informação e do conhecimento. In:

TARAPANOFF, Kira (Org). Inteligência organizacional e competitiva. Brasília: Editora Universidade de Brasília, 2001. p. 111-142.

MORESI, Eduardo Amadeu Dutra. Inteligência organizacional no contexto da sociedade da informação. Revista de Biblioteconomia de Brasília, v. 23/24, n. 4, p. 509-526, especial 1999/2000. Disponível em:<http://164.41.105.3/portalnesp/ojs-

2.1.1/index.php/RBB/article/viewFile/599/597>. Acesso em: 5 mai. 2009.

NASCIMENTO, Nilton Jehan. A inteligência competitiva como apoio ao processo decisório nas organizações empresariais de tecnologia. 2006. 179 p. Dissertação (Mestrado Executivo em Administração) - Universidade do Sul de Santa Catarina, Florianópolis.

OLIVEIRA, Paulo; LACERDA, Juarez. Habilidades e competências desejáveis aos profissionais de inteligência competitiva. Ciência da Informação, Brasília, v. 36, n. 2, p. 4653, maio/ago.2007. Disponível em:

<http://revista.ibict.br/index.php/ciinf/article/view/912/718>. Acesso em: 6 ago. 2009. 
PEREIRA, Adriana Gomes; CIANCONI, Regina de Barros. Potencial de atuação do bibliotecário em atividades de inteligência organizacional: estudo de caso na Universidade Federal Fluminense. Transinformação, Campinas, v. 20, n. 1, p. 83-98, jan./abr. 2008. Disponível em: <http://revistas.puccampinas.edu.br/transinfo/viewissue.php?id=18\#Artigos>. Acesso em: 14 mar. 2009.

PEREIRA, Frederico Cesar Mafra. O processo de conversão do conhecimento em uma escola de atendimento especializado. Encontros Bibli: Revista Eletrônica de Biblioteconomia e Ciência da Informação, Florianópolis, n. 20, $2^{\circ}$ semestre de 2005. Disponível em:< http://www.periodicos.ufsc.br/index.php/eb/article/viewPDFInterstitial/199/303>. Acesso em: 12 ago. 2009.

PEREIRA, Maurício Fernandes et al. In: CONGRESSO VIRTUAL BRASILEIRO DE ADMINISTRAÇÃO, 2004, Florianópolis. A influência da cultura organizacional no desenvolvimento de lideranças. Disponível em: $\langle$ http://www.convibra.com.br/trab.asp?t=7>. Acesso em: 26 maio. 2009.

REZENDE, Denis Alcides. Planejamento de sistemas de informação e informática: guia prático para planejar a tecnologia da informação integrada ao planejamento estratégico das organizações. São Paulo: Atlas, 2003. 185 p.

ROSSETI, Adroaldo; MORALES, Aran Bey. O papel da tecnologia da informação na gestão do conhecimento. Ciência da Informação, Brasília, v. 36, n. 1, p. 124-135, jan./abr. 2007. Disponível em: <http://www.scielo.br/pdf/ci/v36n1/a09v36n1.pdf>. Acesso em: 5 ago. 2009.

SANTOS, Alaneir de Fátima dos; PAIM, Isis. A informação nos modelos organizacionais. Perspectivas em Ciência da Informação, Belo Horizonte, v. 5, n. 1, p. 9-21, jan./jun. 2000. Disponível em: <http://www.eci.ufmg.br/pcionline/index.php/pci/article/view/93/306>. Acesso em: 13 maio. 2009.

SILVA, Francisco Antônio; ESPÍNOLA, Marcos José Costa; VILAR, Rosângela Maria. Gestão do conhecimento e inteligência competitiva: desafios para as organizações produtivas. Informação \& Sociedade: Estudos, João Pessoa, v. 16, n. 1, p. 91-100, jan./jun. 2006. Disponível em:<http://www.ies.ufpb.br/ojs2/index.php/ies/article/view/444/1496>. Acesso em: 6 ago. 2009.

SILVA, Helena Pereira da. Inteligência competitiva na Internet: um processo otimizado por agentes inteligentes. Ciência da Informação, Brasília, v. 32, n. 1, p. 115-134, jan./abr. 2003. Disponível em:〈http://www.scielo.br/pdf/ci/v32n1/15979.pdf〉. Acesso em: 20 ago. 2009.

TARAPANOFF, Kira. Inteligência organizacional e competitiva. Brasília: Editora Universidade de Brasília, 2001.

TARAPANOFF, Kira. Inteligência social e inteligência competitiva. Encontros Bibli: Revista Eletrônica de Biblioteconomia e Ciência da Informação, Florianópolis, n. especial, $1^{\circ}$ sem. 2004. Disponível em: <

http://www.periodicos.ufsc.br/index.php/eb/article/viewPDFInterstitial/289/5278 >. Acesso em: 15 mar. 2009.

TARAPANOFF, Kira; ARAÚJO JÚNIOR, Rogério Henrique de; CORMIER, Patrícia Marie Jeanne. Sociedade da informação e inteligência em unidades de informação. Ciência da Informação, Brasília, v. 29, n., p. 91-100, set./dez. 2000. Disponível em: <http://www.scielo.br/pdf/ci/v29n3/a09v29n3.pdf>. Acesso em: 24 abr. 2009. 
TERRA, José Cláudio Cyrineu. Gestão do conhecimento: o grande desafio empresarial, uma abordagem baseada no aprendizado e na criatividade. 5. ed. rev. e atual. São Paulo: Negócio, 2005. $313 \mathrm{p}$.

VALENTIM, Marta Lígia Pomim. Inteligência Competitiva em Organizações: dado, informação e conhecimento. DataGramaZero : Revista de Ciência da Informação, Rio de Janeiro, v. 3, n. 4, ago. 2002. Disponível em:〈http://www.dgz.org.br/ago02/Art_02.htm>. Acesso em: 15 mar. 2009.

VALENTIM, Marta Lígia Pomim; GELINSKI, João Vítor Vieira. Gestão do conhecimento como parte do processo de inteligência competitiva organizacional. Informação \& Sociedade: Estudos, João Pessoa, v. 15, n. 2, p. 41-49, jul./dez. 2005. Disponível em: <http://www.ies.ufpb.br/ojs2/index.php/ies/article/view/31/1512>. Acesso em: 18 abr. 2009.

VALENTIM, Marta Lígia Pomim; MOLINA, Letícia Gorri. Prospecção e monitoramento informacional no processo de inteligência competitiva. Encontros Bibli: Revista Eletrônica de Biblioteconomia e Ciência da Informação, Florianópolis, n. especial, 1 sem. 2004. Disponível em:

<http://www.periodicos.ufsc.br/index.php/eb/article/viewFile/292/5282>.Acesso em: 22 mai. 2009.

VALENTIM, Marta Lígia Pomim; WOIDA, Luana Maia. Cultura organizacional no processo de inteligência competitiva. DataGramaZero : Revista de Ciência da Informação, Rio de Janeiro, v. 5, n. 4, ago. 2004. Disponível em: <http://www.dgz.org.br/ago04/Art_02.htm>. Acesso em: 15 mar. 2009.

VALENTIM, Marta Lígia Pomim et al. Gestão da informação utilizando o método infomapping. Perspectivas em Ciência da Informação, Belo Horizonte, v. 3, n. 1, p.184198, jan./abr. 2008. Disponível em: <http://www.scielo.br/scielo.php?pid=S141399362008000100012\&script=sci_arttext $>$. Acesso em: 18 mar. 2009.

VALENTIM, Marta Lígia Pomim et al. Pesquisa em inteligência competitiva: organizacional: utilizando a análise de conteúdo para a coleta e análise de dados - Parte I. Transinformação, Campinas, v. 17, n. 2, p. 181-198, maio./ago. 2005. Disponível em:

<http://revistas.puccampinas.edu.br/transinfo/viewissue.php?id=10\#Artigos>. Acesso em: 18 abr. 2009.

VALENTIM, Marta Lígia Pomim et al. O processo de inteligência competitiva em organizações. DataGramaZero - Revista de Ciência da Informação, Rio de Janeiro, v. 4, n. 3, jun. 2003. Disponível em:<http://dgz.org.br/jun03/Art_03.htm>. Acesso em: 15 mar. 2009.

\section{Como citar este artigo:}

DAVOK, Delsi Fries; CONTI, Daiana Lindaura. Fatores facilitadores da inteligência organizacional: o papel das unidades de informação. Rev. digit. bibliotecon. cienc. inf., Campinas, SP, v. 11, n. 2, p.136-158, maio/ago. 2013. ISSN 1678-765X. Disponível em: <http://www.sbu.unicamp.br/seer/ojs/index.php/rbci> 